\title{
Contrast sensitivity function in Graves' ophthalmopathy and dysthyroid optic neuropathy
}

\author{
Maria S A Suttorp-Schulten, Rob Tijssen, Maarten Ph Mourits, Patricia Apkarian
}

\begin{abstract}
Contrast sensitivity function was measured by a computer automated method on 38 eyes with dysthyroid optic neuropathy and 34 eyes with Graves' ophthalmopathy only. The results were compared with 74 healthy control eyes. Disturbances of contrast sensitivity functions were found in both groups when compared with controls. The eyes affected with dysthyroid optic neuropathy showed pronounced loss of contrast sensitivity in the low frequency range, which facilitates differentiation between the two groups.
\end{abstract}

(Br F Ophthalmol 1993; 77: 709-712)

Graves' ophthalmopathy is related to thyroid disease and is characterised by oedema and infiltration of the extraocular muscles and orbital tissue. The resulting exophthalmus can cause damage to the anterior as well as to the posterior regions of the orbit. Exophthalmus per se rarely results in visual loss and when such loss occurs it is caused by secondary lesions - for example, dry eye, keratopathy, eyelid retraction, and/or induced astigmatism. ${ }^{1}$ However, if the posterior part of the orbit and optic nerve are affected dysthyroid optic neuropathy can occur with visual loss. Mechanical compression can precipitate optic nerve neuropathy: increased muscle volume gives rise to intraorbital pressure at the apex and thereby compresses the optic nerve. ${ }^{1-5}$ The exacerbated condition of dysthyroid optic neuropathy is said to occur in less than $10 \%$ of patients with Graves' ophthalmopathy. ${ }^{167}$

Symptoms and signs of dysthyroid optic neuropathy include decreased visual acuity, relative afferent pupillary defect, oedema of the optic nerve head, visual field defects, impairment of colour vision, and abnormal visual evoked responses. The decrease in visual acuity may not be dramatic; about half of the patients with dysthyroid optic neuropathy maintain a visual acuity of $20 / 40(0.5)$ or more. ${ }^{34}$

As the symptoms described above are neither pathognomonic nor invariably present ${ }^{34689}$ the disorder may remain undiagnosed. However, because of the potential for irreversible visual loss, early treatment is important. The treatment of first choice in the group of patients with neuropathy is surgical decompression or high doses of prednisone. ${ }^{101112}$

We have evaluated risk factors and diagnostic methods, including various measures of spatial vision. ${ }^{513}$ The standard ophthalmic test of spatial vision is the Snellen acuity estimate. In general, Snellen acuity yields an estimate of high contrast and high spatial frequency resolution, both of which are readily impaired by simple optical aberration alone. This sensitivity to optical defocus greatly facilitates the process of subjective refraction correction, but reduced contrast sensitivity at low spatial frequencies may present with normal Snellen acuity. As there are various degrees of visual loss within the group of patients with dysthyroid neuropathy, assessment of spatial vision across the frequency and contrast spectrum may reveal visual impairment not readily detected by standard visual acuity measures.

The contrast sensitivity function has proved a useful tool for detecting visual disturbances when Snellen acuity fails to show comparable dysfunction - for example, in glaucoma, ${ }^{14}$ retinal disease, ${ }^{15} 16$ and pterygia. ${ }^{17}$ The clinical potential for contrast sensitivity functions has also been demonstrated in patients with optic neuropathies, ${ }^{18} 192021$ including dysthyroid optic neuropathy. ${ }^{1322}$ This study compares the contrast sensitivity functions of patients with uncomplicated Graves' ophthalmopathy and patients with Graves' ophthalmopathy complicated by dysthyroid optic neuropathy, to determine the value of the measurements in distinguishing between the two groups.

\section{Subjects and methods}

\section{PATIENTS AND SELECTON CRITERIA}

Included in this study were consecutive patients with Graves' ophthalmopathy accompanied by dysthyroid optic neuropathy (group I) and with Graves' ophthalmopathy only (group II).

All patients underwent a complete ophthalmic examination including best corrected Snellen visual acuity, pupillary reflexes, funduscopy, proptosis measurement by Hertl ophthalmometer, ocular motility, Nospecs classification, ${ }^{23}$ and assessment of the total eye score. ${ }^{24}$ Coronal computed tomography (CT) of the orbit was also performed on each patient. Patients with Graves' ophthalmopathy did not undergo visual field testing, as no defects were expected. Patients suspected of dysthyroid optic neuropathy underwent additional visual field examination (Rodenstock perimeter). Visual field defects were defined as scotomas or enlarged blind spot. Colour vision was not assessed. Each patient gave informed consent for participation in the study.

The diagnosis of Graves' ophthalmopathy was based on standard clinical features and enlarged extraocular muscles on coronal computed tomography scan. Several criteria were required for inclusion in group I versus group II.

Graves' ophthalmopathy complicated by dysthyroid optic neuropathy (group I) was diagnosed when apical crowding on coronal computed tomography scan was present and accompanied by one or more of the following 
Table 1 Clinical characteristics of patient groups

\begin{tabular}{|c|c|c|}
\hline & $\begin{array}{l}\text { Group I (Graves' } \\
\text { accompanied by } \\
\text { dysthyroid optic } \\
\text { neuropathy) }\end{array}$ & $\begin{array}{l}\text { Group II (Graves' } \\
\text { only) }\end{array}$ \\
\hline $\begin{array}{l}\text { Number of eyes } \\
\text { Number of patients } \\
\text { Male/female ratio }\end{array}$ & $\begin{array}{l}39 \\
25 \\
4 / 21\end{array}$ & $\begin{array}{l}34 \\
17 \\
1 / 16\end{array}$ \\
\hline $\begin{array}{l}\text { Mean patient age } \\
\text { (years) } \\
\text { (range) }\end{array}$ & $\begin{array}{l}55 \\
(29-79)\end{array}$ & $\begin{array}{l}44 \\
(27-69)\end{array}$ \\
\hline Visual acuity & $\begin{array}{l}20 / 25(0.8) 11 \text { eyes } \\
20 / 30(0.6) 17 \text { eyes } \\
20 / 40(0.5) 4 \text { eyes } \\
20 / 50(0.4) 4 \text { eyes } \\
20 / 60(0.3) 3 \text { eyes }\end{array}$ & $\begin{array}{l}20 / 20(1 \cdot 0) 22 \text { eyes } \\
20 / 25(0 \cdot 8) 12 \text { eyes }\end{array}$ \\
\hline $\begin{array}{l}\text { Optic nerve head } \\
\text { oedema }\end{array}$ & $\begin{array}{l}15 \text { segmental pallor } \\
8 \text { mild swelling } \\
3 \text { marked swelling }\end{array}$ & 0 eyes \\
\hline $\begin{array}{c}\text { Total eye score } \\
0-20 \\
21-30 \\
>30\end{array}$ & $\begin{array}{l}20 \text { eyes } \\
17 \text { eyes } \\
2 \text { eyes }\end{array}$ & $\begin{array}{l}33 \text { eyes } \\
1 \text { eye } \\
0 \text { eyes }\end{array}$ \\
\hline $\begin{array}{l}\text { Visual field } \\
\text { No defects } \\
\text { Defects present }\end{array}$ & $\begin{array}{l}23 \text { eyes } \\
16 \text { eyes }\end{array}$ & not done \\
\hline $\begin{array}{l}\text { Hertl readings } \\
10-15 \\
16-20 \\
21-25 \\
>25 \\
\text { Relative afferent } \\
\text { pupillary defect }\end{array}$ & $\begin{array}{r}0 \text { eyes } \\
4 \text { eyes } \\
31 \text { eyes } \\
4 \text { eyes } \\
3 \text { eyes }\end{array}$ & $\begin{array}{l}1 \text { eye } \\
18 \text { eyes } \\
13 \text { eyes } \\
2 \text { eyes } \\
0 \text { eyes }\end{array}$ \\
\hline
\end{tabular}

symptoms: decrease in optimally corrected Snellen visual acuity of one line or more, a relative afferent pupillary defect, oedema of the optic nerve head, or visual field defect. For patients with a decrease in visual acuity of only one line, inclusion in the test group proceeded only if the patient showed one or more additional signs.

For either group any eye affected with a nonrelated unilateral condition that might influence contrast sensitivity testing was excluded - for example, amblyopia, cataract, and glaucoma. Further, eyes with significant visual loss (less than 20/60) were also excluded, as the contrast sensitivity test in this study was designed to detect low, medium, and high spatial frequency loss; an acuity of less than 20/60 (0.3) would restrict the useful test range to the lowest frequency range only. Patients with a history of orbital decompression surgery were excluded to avoid possible optic nerve complications from surgical intervention.

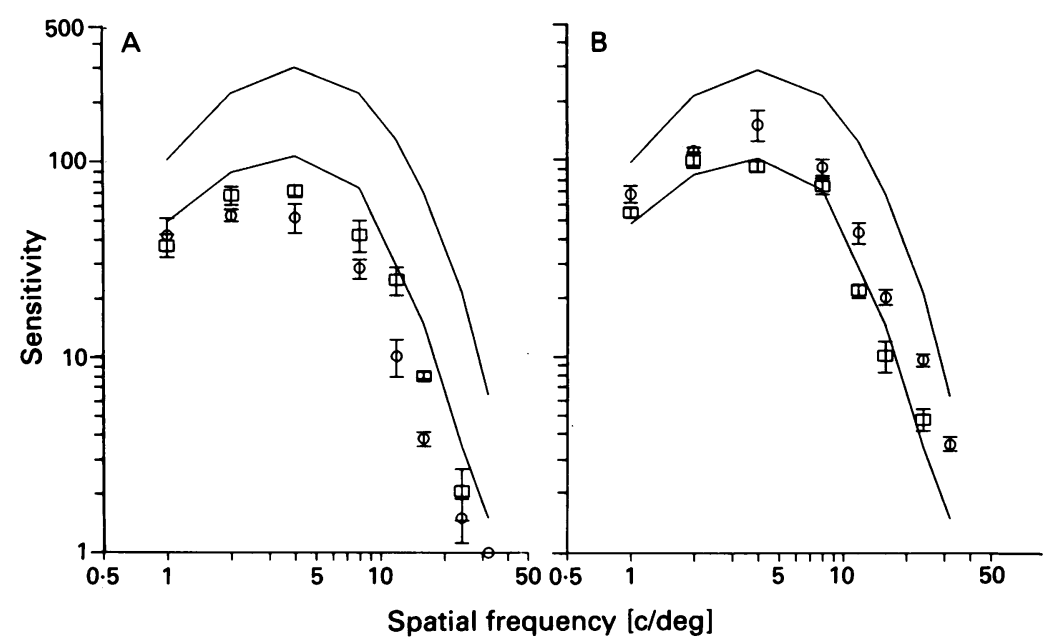

Figure 1 Right eye $(O)$ and left eye $(\square)$ contrast sensitivity functions in a patient with dysthyroid optic neuropathy $(A)$ and a patient with Graves' ophthalmopathy $(B)$. The solid lines represent the median (upper) and 95 th percentile (lower) for a group of normal controls.
In addition to no signs or positive history of dysthyroid optic neuropathy, for all patients of group II, a visual acuity of at least $20 / 25(0 \cdot 8)$ also was required.

Group I consisted of 25 consecutive patients with dysthyroid optic neuropathy (39 eyes); the mean age was 55 years (range 29-79 years). In 11 patients only one eye could be included; three because of unilateral dysthyroid optic neuropathy, seven because of visual acuity of less than $20 / 70(0 \cdot 3)$, and one because of amblyopia.

Group II consisted of 17 consecutive patients with bilateral Graves' ophthalmopathy and no signs of dysthyroid optic neuropathy (34 eyes); the mean age was 44 years (range $27-69$ years). There was no statistical age difference (Student's $t$ test; $p>0 \cdot 1)$ between the two groups. Clinical characteristics for the two patient groups are summarised in Table 1 .

\section{METHODS}

\section{Stimulus and procedures}

Contrast sensitivity function was tested by a computer automated method as described in detail elsewhere. ${ }^{25}$ Briefly, sine wave gratings were generated on a computer controlled cathode ray tube display unit (Joyce Electronics, Cambridge, England). The cathode ray tube was masked with an equiluminant surround. The stimulus field subtended 5 degrees at a viewing distance of $228 \mathrm{~cm}$; space average luminance was $300 \mathrm{~cd} / \mathrm{m}^{2}$. Contrast thresholds were measured with a computer automated method of ascending limits. Contrast was automatically increased at a rate of $1.75 \mathrm{~dB} / \mathrm{s}$. The patient, who was tested under self paced conditions, triggered the random delay (0 to 5 seconds) for the stimulus onset and the subsequent threshold (five thresholds were measured per spatial frequency). Stimulus range was 1 to 32 cycles per degree (c/deg) (spatial frequencies $1,2,4,8,12,16$, and $32 \mathrm{c} / \mathrm{deg})$. The test session began with practice trials at a spatial frequency of $4 \mathrm{c} / \mathrm{deg}$. Further, before each new stimulus block a 2 second preview of the spatial frequency was presented to reduce uncertainty. Testing was performed with optimum refractive correction, natural pupils, and ambient room light; monocular testing was performed with total occlusion of the fellow eye.

\section{Data analysis}

The geometric mean and standard deviation were calculated on line for the five recorded threshold values for each spatial frequency. Patient contrast functions were compared with laboratory standards which include averaged contrast sensitivity functions from normal controls tested across a comparable age range $(n=74)$.

\section{Results}

Figure 1 shows examples of individual contrast sensitivity functions measured from each patient group. In Figure 1A, the contrast sensitivity function from a patient with bilateral dysthyroid optic neuropathy (group I) is depicted. This patient had a Snellen visual acuity of $20 / 40(0 \cdot 5)$ 


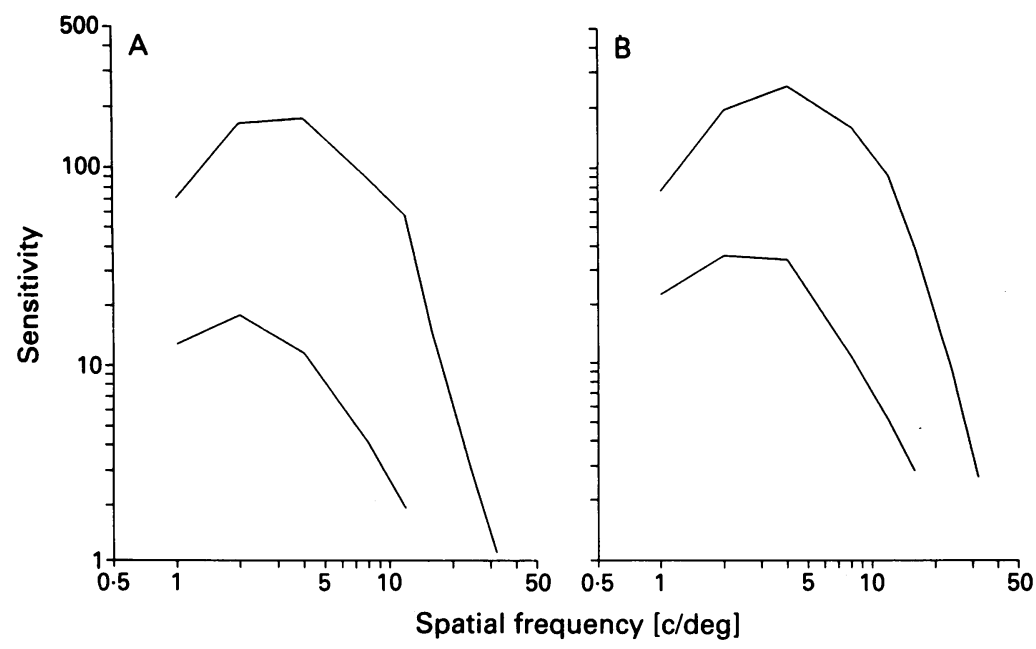

Figure 2 Upper (90th percentile) and lower (10th percentile) limits of contrast sensitivity threshold values for a group of patients with dysthyroid optic neuropathy, group $I(A)$ and with Graves' ophthalmopathy, group $I I(B)$.

right eye and 20/25 (0.8) left eye. All threshold values fall under the averaged data from the normal control group; the solid upper line represents the median and the solid lower line the 95th percentile. In Figure 1B the contrast function of a patient with uncomplicated Graves' ophthalmopathy (Group II) is depicted. This patient had a Snellen visual acuity of $20 / 20(1.0)$ right eye and left eye. While some threshold values fall below the 95th percentile of the control group, compared with the contrast sensitivity function from the patient with dysthyroid optic neuropathy, lower spatial frequency thresholds $(<4$ $\mathrm{c} / \mathrm{deg}$ ) in particular, are above the 95 th percentile range. Neither presence nor kind of visual field defect, presence of relative afferent field defect, optic nerve head oedema and Hertl reading, or severity of ophthalmic symptoms correlated significantly (Student's $t$ test) with the degree or spatial frequency range of elevated threshold values.

The data of Figure 1 are reflected in group I and group II statistical data analyses. Threshold values for the group of patients with dysthyroid optic neuropathy (group I) differ significantly (Wilcoxon $U ; \mathrm{p}<0.01$ ) from those of the control group across the contrast sensitivity spatial frequency range. In comparison threshold values of the group of patients with Graves' ophthalmopathy only (group II) differ significantly (Wilcoxon $U ; \mathrm{p}<0.01$ ) from those of the control group only for the medium and high spatial frequency ranges.

Figure 2 shows the upper and lower limits of the threshold values for the two patient groups (group I, Fig 2A; group II, Fig 2B). The upper line in Figure 2 represents the 90 th percentile that is, $10 \%$ of the threshold values lie above this upper group limit. The lower line is the 10th percentile - that is, $10 \%$ of the threshold values lie below this lower group limit. The lower limit functions indicate that the two patient groups show differences in contrast thresholds that are most pronounced across the lower spatial frequency ranges. This is illustrated by Figures 3 and 4 which show the relation between visual acuity and contrast sensitivity thresholds in one of the lower spatial frequencies $(2 \mathrm{c} / \mathrm{deg}$ ) for patients with dysthyroid optic neuropathy and patients with Graves' ophthalmopathy. In both groups one can see low threshold values in this frequency; this does not have a pronounced relation with the visual acuity. The values for group I are much lower than those for group II.

\section{Discussion}

Contrast sensitivity measures are a sensitive parameter for detecting disturbances in visual function. It has been shown previously that contrast sensitivity functions can reveal visual impairment in optic neuropathies even in patients with normal or near normal Snellen visual acuity. ${ }^{18-21}$ Snellen visual acuity only yields information about resolution of optotypes of standard high contrast. In comparison, contrast sensitivity measures across the spatial frequency range may yield additional diagnostic information including subtle visual loss. In general, our patient material confirms these conclusions.

We found disturbances in contrast sensitivity in almost all patients with either Graves' ophthalmopathy complicated by dysthyroid optic neuropathy (group I) or uncomplicated Graves' ophthalmopathy (group II). While there was considerable overlap in the contrast sensitivity

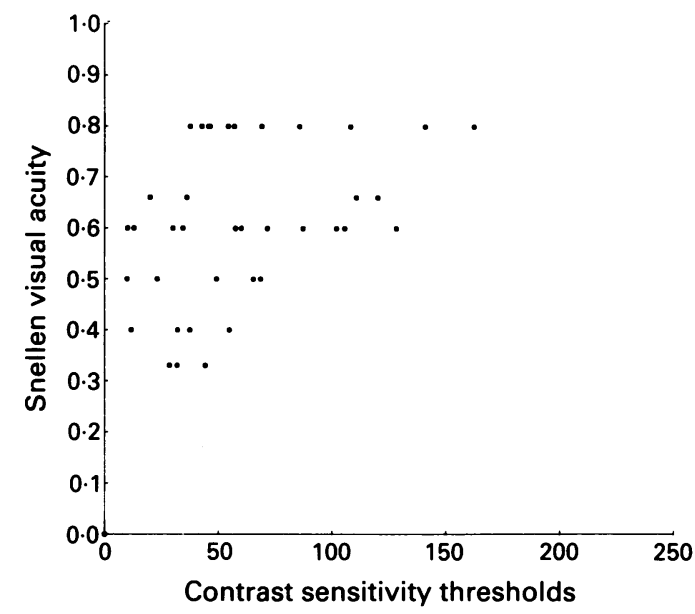

Figure 3 Contrast sensitivity thresholds at 2 cycles per degree ( $x$ axis) versus Snellen visual acuity ( $y$ axis) in patients with dysthyroid optic neuropathy (group I).

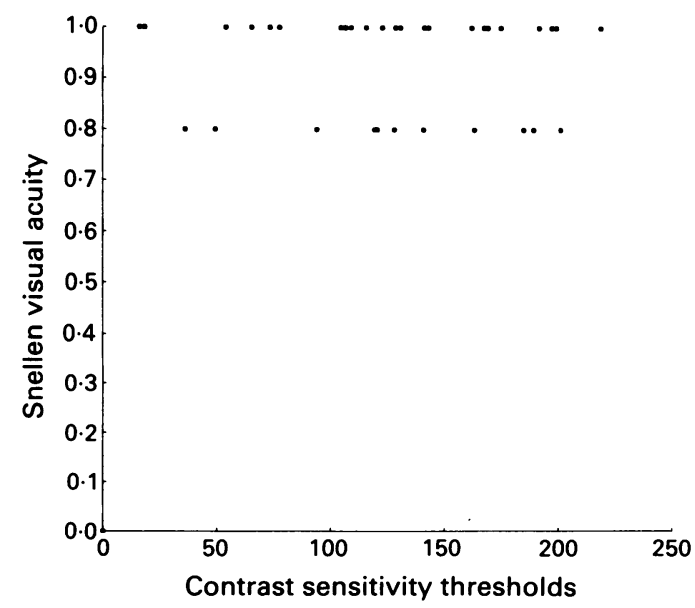

Figure 4 Contrast sensitivity thresholds at 2 cycles per degree ( $x$ axis) versus Snellen visual acuity (y axis) in patients with Graves' ophthalmopathy (group II). 
functions in terms of abnormally elevated threshold values from the two patient groups, group I patients showed greater loss within the low frequency range. The latter finding may assist in differential diagnosis since patients with low spatial frequency contrast thresholds that fall below the lower limit of that for uncomplicated Graves' ophthalmology patients (group II) are most likely to have accompanying dysthyroid optic neuropathy. Further, no patients in group I showed normal contrast sensitivity functions, not even those with a visual acuity of $20 / 25$ (see Table 1). Thus, a normal contrast sensitivity function precludes the diagnosis of dysthyroid optic neuropathy.

In seven patients the measurement of contrast sensitivity function was repeated after therapy. In six of them improvement was observed.

The primary aim of this study was to evaluate the clinical application of the contrast sensitivity function for assessing the visual function of patients with Graves' ophthalmopathy. In addition to its usefulness in describing spatial vision, the significant low spatial frequency differences between patients with uncomplicated Graves' ophthalmopathy compared with patients with Graves' ophthalmopathy complicated by dysthyroid optic neuropathy may facilitate differential diagnosis between the two conditions and monitoring of the disease.

1 Jacobson DH, Gorman CA. Endocrine ophthalmopathy: current ideas concerning etiology, pathogenesis, and treatment. Endocrine Rev 1984; 5: 200-20.

2 Fells P. Orbital decompression for severe dysthyroid eye disease. Br f Ophthalmol 1987; 71: 107-11.

3 Trobe JD, Glaser JS, Laflamme P. Dysthyroid optic neuropathy. Clinical profile and rationale for management. Arch Ophthalmol 1978; 96: 1199-209.

4 Kennerdell JS, Rosenbaum AE, El-Hoshy MH. Apical optic nerve compression of dysthyroid optic neuropathy on com puted tomography. Arch Ophthalmol 1984; 99: 807-9.
5 Feldon SE, Muramatsu S, Weiner JM. Clinical classification of Graves' ophthalmopathy. Identification of risk factors fo optic neuropathy. Arch Ophthalmol 1984: 1469-72.

6 Neigel JM, Rootman J, Belkin RI, Nugent RA, Drance SM Beattie CW, et al. Dysthyroid optic neuropathy. The crowded apex syndrome. Ophthalmology 1988; 95: 1515-21.

Trobe JD. Optic nerve involvement in dysthyroidism. Ophthalmology 1981; 88: 488-92.

8 Schaefer SD, Merritt JH, Close LG. Orbital decompression for optic neuropathy secondary to thyroid eye disease. Laryngoscope 1988; 98: 712-6.

9 Guy JR, Fagien S, Donovan JP, Rubin ML. Methylprednisolone pulse therapy in severe dysthyroid optic neuronisolone pulse therapy in severe dysthy
pathy. Ophthalmology 1989; 96: 1048-53.

10 Fells $P$. Thyroid associated eye disease: clinical management. Lancet 1991; 338: 29-32.

11 Mourits MPh, Koornneef L, Wiersinga WM, Prummel MF Berghout A, van der Gaag R. Orbital decompression for Graves' ophthalmopathy by inferomedial, by inferomedial plus lateral, and by coronal approach. Ophthalmology 1990 97: 636-41.

12 Utiger RD. Treatment of Graves' ophthalmopathy. $N$ Engl f Med 1989; 321: 1403-5.

13 Mourits MPh, Suttorp-Schulten MSA, Tijssen RO, Apkarian $P$. Contrast sensitivity and the diagnosis dysthyroid optic neuropathy. Doc Ophthalmol 1990; 74: 329-35.

14 Sample PA, Juang PSC, Weinreb RN. Isolating the effects of primary open angle glaucoma on the contrast sensitivity function. Am $\mathcal{F}$ Ophthalmol 1991; 112: 308-16.

15 Wolkstein M, Atkin A, Bodis-Wollner I. Contrast sensitivity in retinal disease. Ophthalmology 1980; 87: 1140-9.

16 Marmor MF. Contrast sensitivity versus visual acuity in retina disease. Br F Ophthalmol 1986; 70: 553-9.

17 Lin S, Reiter K, Drcher AW, Frucht-Pery J, Feldman ST. The effect of pterygia on contrast sensitivity and glare disability. Am f Ophthalmol 1989; 107: 407-10.

18 Drucker MD, Savino PJ, Sergott RC, Bosley TM, Schatz NJ, Kubilis PS. Low-contrast letter charts to detect subtle Kubilis PS. Low-contrast letter charts to detect

19 Skalka HW. Comparison of Snellen acuity, VER acuity, and Arden grating scores in macular and optic nerve diseases. Arden grating scores in macular

20 Zimmern RL, Campbell FW, Wilkinson IMS. Subtle disturbances of vision after optic neuritis elicited by studying contrast sensitivity. F Neurol Neurosurg Psychiatry 1979; 42:

21 Nordmann JP, Saraux H, Roullet E. Contrast sensitivity in multiple sclerosis. Ophthalmologica 1987; 195: 199-204.

22 Weatherill J, Yap M. Recovery of contrast sensitivity following bilateral orbital decompression: a case report. Am F Opt Phys Optics 1985; 62: 715-9.

23 Werner SC. Modification of the classification of the eye changes in Graves' disease. Am $\mathcal{F}$ Ophthalmol 1977; 83: 725-7.

24 Prummel MF, Mourits MPh, Berghout A. Prednisone and cyclosporine in the treatment of severe Graves' ophthalmopathy. N Engl F Med 1989; 321: 1353-9.

25 Apkarian $\mathbf{P}$, Tijssen $R$, Spekreiise $H$, Regan D. Origin of notches in CSF: optical or neural? Invest Ophthalmol Vis Sci 1987; 28: $607-12$. 